\title{
Technology, economic development, and sustainability: The case of Latin America
}

\author{
Jorge Martínez-Contreras*, Raúl Gutiérrez-Lombardo** and \\ Marcela Lombardo-Otero** \\ * UAM-Iztapalapa, Mexico \\ Phone: +52 57244785 , Fax: + 5256125682 \\ Email:jmc@xanum.uam.mx \\ ** CEFPSVLT, SEP, Mexico \\ Phone: +52 5661 4987, Fax: +52 56611787 \\ Email: lombardo@servidor.dgsca.unam.mx
}

\begin{abstract}
This contribution is divided in three parts. The first draws attention to the problem of the new global order and the complex realities lived in the many diverse countries of Latin America. The second part analyzes the problem of identities and culture. We try to answer two fundamental questions: 1) How the question of cultural identity and problems concerning resistance and integration in Latin America arise in the framework of the neo-liberal model? 2) What is the role of the media in the current redefining of new identities and new cultural borders? The third part of the paper refers to the problems of globalization and sustainable growth in the modernity-postmodernity debate in Latin America. In particular, we analyze the preservation and/or conservation ecological question.
\end{abstract}

\section{THE NEW GLOBAL ORDER}

There are numerous authors who agree in asserting that the information revolution which occurred in the last decades and the globalization of the economy are phenomena that are perceived as proofs of the emerging of a seemingly definitive age. This era will be characterized by a homogenization of human societies all over the world, by an increasingly strong embracing of western ways (while peoples 
throughout the face of the globe give up old traditions, customs, and heritage) and, more generally, by a disappearance of local cultures. From here on, claims Francis Fukuyama, in his essay on the end of the history, 'everything will be more or less the same, no alternatives to the actual world will exist' .

This assertion, as Edgar Samuel Morales pointed out, presupposes that the actual world, the one that really deserves to be called actual, is that of the United States whose citizenship Fukuyama bears. Or maybe it is the world of airports, freeways and malls that follow the American fashion for the urban-suburban in the main European metropoles, some Asian cities, and even a few capital cities in Latin America. They all undeniably resemble each other. The world is constituted, so Fukuyama says, by all those social spaces where the market economy has an absolute rule: those places where a large share of the population sports westernstyle clothes and where people have access to technological products from the information industry. Thus, Fukayama claims, the world will be like a big global village ${ }^{2}$.

Nevertheless, assertions like Fukuyama's stand in absolute contrast to the social, economic and political relations produced in every corner of the world, especially those complex realities lived in the many diverse countries of Latin America. In fact, these suppositions take for granted that, in the west, there is a sort of continuum where everything is free competition, equal access to consumption, homogeneous thinking, and material culture. Now, we all know that, contrary to the above fantasy, in western countries there are strong social disparities and strong economic contrasts between the different social groups in the various populations that arise not just from the fact that these countries have been formed by several strikingly different local groups but also because they have been forced to integrate large masses of population that came from faraway places. Immigrants are a part of their social landscapes ${ }^{3}$.

We must not forget that the highly praised globalization of the economy is just the expansion of the most powerful transnational companies. The beneficiaries of the wide circulation of Asian, European and North American commodities are mostly countryless, ill-defined corporations with no clear origins. These financial entities switch their capital from one country to another, causing false economic booms and national bankruptcies in just a few days. In Latin America, the cases of Mexico, Argentina, and Venezuela exemplify pretty well the nasty doings of these fuzzy organisms, which are sometimes linked to obscure interests that set governments and sovereignties at bay. Furthermore, we should point out that there are strong inequalities as a result of the very access to the now-globalized markets. There is no fair and equal opportunity access for all companies. It is a well-known fact that in very specific domestic markets there are always companies that receive favours, preferences, subsidies, and even monopoly entitlements from governments that support so-called neo-liberalism. In addition, we should state that the transnational companies' Big Bang did not happen by fortuitous or miraculous circumstances. Nor did it happen by spontaneous generation. Actually, it had its origins in the centuries-old technological domain which favoured those countries that had previously engaged in conquest wars that endowed them with lands and markets. Another advantage for these countries came from the domination and colonization imposed on peoples of a traditional kind and the ransacking of natural resources in lands subjugated by colonialism. The globalization of the economy, 
such as it is currently practiced, is nothing but the expansion of large industrial and commercial companies and their technologies that, when applied in their own original countries, ruined micro, small and middle-sized entrepreneurs by forcing them into bankruptcy in an atmosphere of unfair competition. One incentive behind globalization is that big transnational companies move away from their original countries when their workers demand better labour conditions and higher wages, and establish themselves in countries where labour is ten times or more cheaper in spite of initial training expenses. Such deeds cause a continuous loss of hundreds and thousands of jobs even in highly developed countries ${ }^{4}$.

The above point is closely tied to the theory proposed by the authors of the report of the Trilateral Commission. This theory, described by Lorenzo Córdova as a consequence of the end of the postwar economic boom, fostered ferocious and harsh criticism of the social regime and democratic achievements entailed in the welfare state of the so-called neo-liberals. Thus, the welfare state was charged with responsibility for the political and economic crises that flooded capitalist countries, especially the United States, in the 1970s.

Aiming to propose feasible solutions to face both the underlying economic recession and the diminished credibility of their political structures and the opposition to them, the First World countries in Europe, America and Asia appointed a task group called the Trilateral Commission. This committee was commanded to do research on the causes that had triggered the crisis. The results of the analysis made by Professors Michael Crozier, Samuel P. Huntington and Joji Watanuki were summarized in the paper, The Crisis of Democracy: Report on the Governability of Democracies to the Trilateral Commission.

In the report, the authors reach the generic conclusion that the excess of democracy which characterized the welfare state had generated a situation of ungovernability that could not be solved unless there was a reduction in the social and democratic achievements obtained by means of welfare state policies ${ }^{5}$.

Crozier, Huntington and Watanuki imputed the welfare state with the following four charges: a) a delegitimation of authority and mistrust of the rulers' leadership (problems with basic elements of every society; in the authors' view, these troubles were caused by the pursuit of the democratic virtues of individual equality and freedom); b) an overloading of state structures caused by the inefficiency of government aimed at the spread of democracy as a result of political participation, by an uneven increase in government activities, and by an exacerbation of the inflationary tendencies in the economy; and c) intensified political competition. This competition can be considered as a foundation of democratic states but disrupts interests and causes political parties to fracture if it grows uncontrolled. Out-of-hand intensified political competition causes phenomena such as 'ill-pluripartisanism', like that which has characterized Italy's political life where major decisions are not taken by big political parties but are made instead by small political parties. Under these circumstances, small political parties become fundamental elements in the formation of congressional majorities. In this sense, the authors point out, democracies can only be handled on the grounds of consent but they are very hard, if not impossible, to reach in the complex multiparty regimes that define most contemporary democratic societies. Finally, d) there is a parochialism that democratic tendencies in the welfare state have generated in international structures. 
Among the features pointed out by the authors of the report, there are two that are most often quoted by neo-liberal writers, namely, the second one (the overloading thesis) and the third one (the exaggerated vitality of the democratic multiparty system $)^{6}$.

Accordingly, José Fernández has called attention to the fact that, in the face of governability crises caused by overloading and by state intervention in the economy, neo-liberals have tried to substitute interventionist strategies using privatization as a first remedy. That is, they allow the market to retain its own dynamics without the obstacle of state intervention. A second remedy aimed at diminishing the overload of demands plainly means diminishing democracy ${ }^{7}$.

Something similar happens in the so-called technological revolution. There have been huge advances in telecommunications, means of transportation, and especially in informatics, that allow a vertiginous flow of human groups, ideas, fashions, information, and so forth. But this situation has caused several problems. First, not even in the most developed countries does everyone have easy access to advances in informatics or cybernetics. It is true that technological innovations will continue to originate particularly in highly developed countries and it is also true that research on these matters will keep on developing mostly there, but there is no guarantee that people in those countries will have an equal right to goods produced by technological advances. On the other hand, the development of informatics and robotics has given rise to the so-called post-industrial era which, in itself, is turning into a source of unemployment for thousands of workers whose services are rendered unnecessary day after day ${ }^{8}$.

This new industrial revolution, the high tech revolution, as it is often called, has had adverse effects on large masses of humankind and severe repercussions on people's development and standards of living.

Once high technology was introduced into the large transnational monopolies, their production rose in an extraordinary way, thus multiplying their power. But, given the magnitude of their production, the combined markets of their own countries and influence zones became insufficient and were rather restricted in fully consuming it. Hence, big monopolies needed to transform the whole earth into a single market. So they needed trade to open up in every country and free trade to be set up. This is how the globalization theory got started.

Globalization is defined as a new productive process on a world scale. Production, technology and commercialization are linked in world-integrated chains of added value. This fact demands liberalization of trade, capital, services, and technology. In turn, the neo-liberal doctrine fulfils its role by introducing reforms inside countries. In this way, state participation in production and services is suppressed and there is a growing tendency to eliminate regulations and controls in the whole area of production. In the first instance, this proceeds to the privatization of public companies with the aim of shifting power from the hands of the state to those of private enterprises.

It is important to take into account the fact that, to compete successfully in the globalizing process, a sound capacity of industrial development and high technology is required. That is why, according to United Nations' reports, ever since this policy was propelled forward at a world level, the main countries that have reinvigorated their industrial development are the United States, Japan and some European powers. On the other hand, the production capacities in those 
industrialized countries also reached a high rate of concentration when high tech electronic equipment for productive processes is taken into account.

In the above mentioned industrialized countries are concentrated $82.3 \%$ of the world's total production capacities, while the rest of the countries, with a heavy leaning towards China and the newly industrialized Asian countries, share only 17.7\%. In Latin America is concentrated only $4.8 \%$.

In just ten years' existence of the new world order based on economic globalization and neo-liberalism, this deeply unfair disproportion of the world's distribution of development and industrial capacity has had consequences that could not be more disturbing and severe. Here are some facts:

1. They have broken social cohesion, thus aggravating poverty and unemployment. Not even highly industrialized countries like Germany and the United States have escaped from high unemployment rates but, in the underdeveloped countries, the effects have been stronger.

2. They have concentrated the world's wealth to an utterly monstrous point. Of course, the existence of high concentration rates that benefit a minority can be observed; this is generally associated with large transnational monopolies.

According to data registered with the help of the GINI coefficient technique, we can see that, between the years of 1960 and 1989, there was an increase in inequality between the richest and the poorest countries. That is reflected in a change in this coefficient from 0.44 to 0.55 (the higher the coefficient, the higher the inequality).

Also, inequality has grown as measured in terms of deciles (tenths of the total population). That is, if we take the 20 percent richest and the 20 percent poorest of the population, we find a disparity that grew from 11.1 to 17.1 in the same period.

The 1996 World Report of the United Nations for Industrial Development states that it is possible to foresee that world inequality will grow as a consequence of the globalization process.

\section{IDENTITY AND CULTURAL RESISTANCE}

Other writers agree with the thesis that one of the most controversial consequences of the neo-liberal expansion is the awakening of identities. The decade of the 1970s was marked by the abandonment of social classes while the 1980 s placed stress on social actors' theories. The big concern of the current decade is a discussion about national, social, and cultural identities.

In order to analyze identity and resistance in Latin America, Marià Nazareth Ferreira states some preliminary remarks. There are two questions that are necessary to locate the problem, namely: 1) How does the question of cultural identity and problems concerning resistance and integration in Latin America arise in the framework of the neo-liberal model? and 2) What is the role of the media in the current transformation that is redefining new identities and new cultural borders?

To answer these questions, it will be necessary to refer to the recent transformations that the world is undergoing, among them, new ways of establishing third world countries in the world economy by means of schemes imposed by neo-liberalism ${ }^{10}$. 
Defenders of neo-liberal doctrines have characterized the 1980s' decade as lost. However, from the point of view of self-knowledge, it was only during the past fifteen years that Latin America got rid of several simplistic theories that harmed a realistic self-view. A realistic self-view has several advantages over others, namely, it is founded on actual Latin American problems and is developed by domestic intellectuals and scientists. These specialists have been able to reevaluate and overcome old concepts and dichotomies, allowing them to think both about the new geopolitical realities and to understand questions such as those proposed above $^{i 1}$.

Integrated in a downward fashion ever since the time of the discoveries, Latin America today is living under a new form of integration. Nowadays, the integrationist discourse acts by means of a neo-liberal model: the homogenization of markets, culture, and consumption. Participation of the media is required in the formation of consent needed for the acceptance of such a discourse ${ }^{12}$.

An avalanche of arguments, laws, agreements, and other figures is directed towards consent, setting up a political and economic scheme that has been moulded from outside. Ulloa ${ }^{13}$ refers to this universe as the integration rhetoric, which is constituted by discourses expressed from different positions, that seeks to legitimize the neo-liberal model by creating favourable public opinion and by forming subtle ways of embracing neo-liberal ideas in different parts of society. These rhetorical statements are transcribed and spread by the media. They echo the International Monetary Fund's mermaid songs in attempting to define globally our economic destinies in the twenty-first century.

Changes on the road to globalization, proposed by a new phase in monopolistic accumulation of international capital, have brought harsh consequences for cultural matters, insofar as these are suffering from an unprecedented transnationalization process never before experienced in history. The expansion of cultural industries, the appropriation and privatization of the media, the expansion and homogenization of information networks, the weakening of the nation-state and the blurring of the distinction between public and private are deemed necessary conditions to warrant efficiency and rationality in the markets ${ }^{14}$.

Marià Nazareth Ferreira has pointed out that the most important feature is the internationalization of cultural industries which, joined by internationalization of other parts of the economy, is strongly interfering with cultures in every corner of the world by several means, and looking forward to homogenizing cultural goods and markets of symbolic items of every kind.

Thus, the crucial question refers to the system of information and communication. The expression of new technologies related to information illustrates the strategic place of the communication system in the neo-liberal new order, as long as it is no longer a state-run public entity but a commodity that follows market laws ${ }^{15}$.

In this sense, the system of communication and information becomes a reproducer of the dominant culture on a world scale, reproducing the system as a whole. Homogenization of cultural items, markets, tastes, and consumption is one of the most significant tasks of this new communication order. Still, social movements and cultural processes that resist the drive to homogenization arise, due to the peculiar nature of these dominating forms that are expressed through an 
uneven development. Beginning with these resistances, it is possible to evaluate the existence of essential constituents of cultural identities ${ }^{16}$.

If the concept of identity, whether national or cultural, started from factors such as land, race, language, and religion, it will be necessary to evaluate how these ingredients have transformed their representations during the past decades. We will need to reset the relationship between the unity and the diversity of ethnic groups, knowledges, lands, and languages, in order to understand and interpret the conformity of new identities (cultural, regional, national, and transnational) in which new sectors of society recognize themselves, and to analyze new symbols and identity models that emerge in different contexts as a result of an unfair match between tradition and modernity and between primitive and postmodern in mestizo America ${ }^{17}$.

From these considerations, we draw at least one conclusion: there is not a single, unified identity and culture in Latin America but several identities and several cultures: just like all the countries that form it, Latin America is pluricultural $^{18}$.

Particularly in relation to the media, one of the effects that have been produced in folk cultures is that all direct forms of social interaction are substituted by mediated forms of a wider communication system, where the new forms constitute a foreign or distant element of that reality. Symbolic markets are reorganized in a fashion that runs contrary to tradition. Traditional folk cultures are reconstituted in accordance with this view. There is a massification of consumption patterns and new industrial techniques are introduced with regard to the production of commodities ${ }^{19}$.

Hence, massification does not eliminate traditional cultures but changes them in a substantial way that diminishes their meaning in everyday life. A contradictory position can be seen with regard to the Latin American masses, even under the conditions of fragmentation and multiplicity that characterize Latin American reality. This position tries to gain recognition while attempting to be distinguished as different from other groups in society. But, at the same time, as groups are trying to assimilate into society as a whole, they are trying to develop a sense of belonging. One of the ways that make these processes of selfacknowledgment and self-esteem possible is through everyday life, from a daily construction drawn from experiences, memories, and consciousness of the present, including all its rights and wrongs. 'A whole deal of folk culture has been repression, machismo, an authoritarian way that has been preserved with diverse excuses, hollow rituals, but also a fair share of these cultures has been folk culture, imagination, creativity. Thus, the history of Latin America is also the history of the masses' culture ${ }^{20}$.

\section{GLOBALIZATION AND SUSTAINABLE GROWTH.}

Rigoberto Lanz ${ }^{21}$. maintains that, in Latin America, there has been an ongoing, lively debate that unveils some tracks. This debate has likenesses and differences with its European post-capitalistic counterpart. The Latin American debate shows a certain resistance, both attitudinal and theoretical, to assuming all the implications of the modernity-postmodernity debate. 
Today, the fuzzy times of crisis have transmuted the language of imperialism, class struggle, national liberation, bourgeois democracy, new man, and dependence into more civilized keywords such as governability, sustainable growth, full democracy, integration, and new economic order. Modern friends, says Lanz, would like to find some ontological ground in identity to refill the void of the portable, fleeting, and ephemeral concept of Latin America. In the face of the theological triad of market, technology, and democracy, contemporary thought in Latin America refers back to Habermas' statement, 'everything within the bounds of the rule of the law, 22 .

There is a common background shared by all defenders of modernity: 1) a collective allergy to every sort of irrationalism; 2) a suspicious, epistemic amnesia regarding the hot issue of power; 3) a discreet retreat away from social change topics, now transmuted into governability; 4) a submissive attachment to an Enlightenment minima moralia for cloudy times; 5) an unrestrained acritical bent towards technological logic; 6) a marked tendency to empty the crucial debate on democracy of its substantive contents; and 7) an evident difficulty in thinking about economy apart from market terrorism ${ }^{23}$.

On the side of postmodern thought, it is possible to track a backdrop that communicates theoretical developments from different writers. In their common background, there is an easily distinguishable screen that reflect some signals: 1) the rise of a new sensitivity that is expressed in every discursive fold of social practices; 2) the deconstructivist dismantling of the main rational pivots of modernity; 3) a strong bent for relativism in all fields; 4) a substantial regaining of multiculturalism; 5) an acrimonious impeachment of every form of centrality, totalism, and hierarchy; 6) the rise of a new vision and sensitivity that keeps its distance from dominating rationality; and 7) a minimalist ethics founded on a new sociality ${ }^{24}$.

What is the shared feature of the common background of Latin American postmodernism? Lanz believes that certain provisional characteristics can be singled out, namely: 1) a harsh questioning of tropical "picturesquism" that has been hiding behind the mask of patriotism, naive indigenism, and the several variants of a traumatic identity theory; 2) a breaking away from the dominant epistemological paradigms that have prevailed in academic culture; 3) a huge effort to reinterpret the very concept of Latin America beginning from the theoretical tension generated inside the modes of cultural configuration; 4) a constructive regaining of the anthropologically hybrid character of the area in the face of the inexorable techno-cultural processes of globalization; 5) a full questioning of the traditional agenda of ecology that focuses on technical rationality and the unfeasibility of the reigning "ecopredator" model; 6) a questioning of the development culture so as to start lifting the ideological veil of the different discourses at stake; and 7) a criticism of the neo-conservative instrumentation of postmodern thought ${ }^{25}$.

When the ecological question is focused under this view or under what is now called sustainable growth, we cannot help understanding it as part of a crisis that radically questions those values in the western tradition that, ever since the Bible, have held that the world was created for the exclusive benefit of human beings. This crisis also questions, in a particular way, principles and values of the Enlightenment. The Enlightenment valued to the highest degree instrumental 
rationalism, which held as a paradigmatic principle that progress joined by advances in technology will benefit and change mankind. Such values were never questioned in the nineteenth-century utopias proposed by Hegel, Marx, Engels, Comte, and others in their positivistic and socialist revisions.

With regard to nature, the Enlightenment hoped to apply the scientific revolution of the seventeenth-century. Nature should be tamed for the benefit of men, and purged of noxious or non-productive species. Nature had to be transformed, for man's benefit, into a garden where only useful or beautiful and notso-dangerous plants and domestic animals existed. Thus, the great philosopher Locke said: 'Land that is left wholly to nature ... is called, as indeed it is, waste.'

Buffon went further in proposing a statement that could be adopted by all destroyers of ecosystems and all land developers as a justification for their actions: 'La Nature brute est hideuse et mourante; c'est Moi, Moi seul qui peut la rendre agréable et vivante: desséchons ces marais, anomons ces eaux mortes en les faisant couler (...) mettons le feu à cette bourre superflue, à ces vieilles forets déjà demi consommées; achevons de détruire avec le fer ce que le feu n'aura pu consommer: bientôt, au lieu du jonc, des nénuphars, dont le crapaud composait son venin, nous verrons paraitre la renoncule, le trèfle (...), des troupeaux d'animaux bondissants fouleront cette terre jadis impraticable ...'

We have lost, perhaps for the planet's future benefit, certainties, beliefs, and utopias about the domesticity of the earth. Many thinkers have attributed the origin of many of our cultural evils to the end of teleological utopias. On the contrary, we believe that utopias lead us into believing the existence of those non-existent places, those 'no places' that Moro, who coined the term, told us about.

Nevertheless, there do not seem to exist clear options to instrumental rationalism and to the belief that a continuously supported growth that can be sustained in nature are the only solutions to ease the material evils suffered by the majority of humanity.

In Mexico, talk of sustainability is omnipresent in politics, culture, and especially in fashionable economic theories that attempt to justify the kind of economic development that some are trying to impose on our country. Sustainability has become an ingredient in official speeches as well as in speeches in so-called civil society. But this is just a theoretical advance at best, since the very condition of the national ecosystem shows that Brundtland's formula has not worked in Mexico. The alleged improvement in material conditions for mankind has brought a larger and faster destruction of ecosystems; it has not really improved the living standards of society in general. Pollution in big cities is out of control even when official speeches claim that it can be managed within twenty or thirty years. Desertification of farmlands, destruction of ecosystems, and the irreparable loss of biodiversity are out of real control. On top of this, the Catholic church in Mexico is still encouraging unrestrained demographic growth. This population growth will, by itself, prevent any attempt at sustainable growth.

Hence, we think that the acknowledgment of this problem in political discourse is a useful step because it has opened up a debate on this reality. But the fundamental step, the enactment of protective laws and their strict enforcement, still faces an uncertain future.

Our cultural heritage stems from admiring the beauty of the Parthenon but also from realizing that such a monument was built at the expense of deforesting a 
whole mountain. This urbanization process, that has been going on for only ten thousand years, a tiny interval in biological terms, has joined with the processes of agriculture and animal, powered to a point of endangering the existence of biodiversity on our planet.

What solutions can be offered? There is no sustainable growth without preservation and conservation. These two concepts are different and opposed. Preserving means that we should have ecosystems with no human participation whereas conserving means that humans ought to contribute to the survival of ecosystems, acting on them in a positive way. Probably, ultimately, conservation and preservation are concepts that are antagonistic to that of sustainability. Thus, sustainable growth can perhaps aspire to or, at the most, slow the pace of the destruction of ecosystems as well as any greater pollution control. Up to a certain point, the sustainability speech is not fully sustainable.

1 Quoted in Morales Sales, Edgar Samuel, La cultura latinoamericana en la aldea global, Cuadernos Americanos, ano X, vol. 60 (Noviembre-Diciembre 1996), UNAM, Mexico, (pp. 3744), p.37

$2 \quad$ Ibid, p. 37.

$3 \quad$ Ibid, p. 38.

$4 \quad$ Ibid, pp. 38-39.

5 Córdova Vianello, Lorenzo, Liberalismo, democracia, neoliberalismo e ingobernabilidad, Revista Mexicana de Sociologia, ano LVIII, vol. 4 (Octubre- Diciembre, 1996), UNAM, Mexico (pp. 335), p. 23.

$6 \quad$ Ibid, pp. 25-26.

7 Fernández Santillan, José, Filosofia politica de la democracia, Fontamara, S.A., Mexico, 1994, p. 101. (quoted by Córdova, op. cit., p. 27).

$8 \quad$ Morales Sales, op. cit., p. 40.

9 Ferreira, Mara Nazareth, Identidad y resistencia cultural en América Latina: Algunas consideraciones preliminares, Cuadernos Americanos, ano X, vol. 60 (Noviembre-Diciembre, 1996), UNAM, México (pp. 45-53), p. 45.

$10 \quad$ Ibid, p. 46.

11 Ulloa, S. Alejandro, Identidad cultural e integración en América Latina. Desafos y perspectivas, En torno a la identidad latinoamericana, México, 1992 (quoted by Ferreira, op. cit., p. 46).

12 Ferreira, op. cit., p. 47.

13 Ulloa, op. cit., p. 47.

14 Ferreira, op. cit., p. 47.

15 Ibid, p. 47 .

$16 \quad$ Ibid, pp. 47-48.

17 Ulloa, op.cit., p. 106 (quoted by Ferreira, op.cit., pp. 48-49).

18 Ferreira, op.cit., p. 49.

19 Ibid, p. 52.

20 Monsiváis, Carlos, interviewed by Martha Elena Montoya Vélez (quoted by Ferreira, op. cit., pp. 52-53).

21 Lanz, Rigoberto, La ventaja de llamarse América Latina, Cuadernos Americanos, ano X, vol. 60 (Noviembre-Diciembre, 1996), UNAM, México, pp. 54-62

22 Ibid, p. 55.

${ }_{23}$ Ibid, pp. 54-55.

${ }_{24} \quad$ Ibid, p. 56.

25 Ibid, p. 57. 